\title{
A AUDIODESCRIÇÃO E OS ELEMENTOS VISUAIS DO ESPETÁCULO
}

\author{
The audiodescription and the visual elements of the spectacle
}

De la audiodescripción y los elementos visuales del espectáculo

Larissa Hobi Martins*

\begin{abstract}
Resumo
A audiodescrição (AD) é um recurso que vem paulatinamente sendo estudado, pesquisado e operacionalizado em uma perspectiva da inclusão cultural, proporcionando o acesso e a fruição de pessoas com deficiência a diversos produtos/espaços culturais. Partindo do pressuposto de que o teatro, a dança, as artes visuais, o cinema, o circo, a performance, os programas televisivos, dentre outros bens/produtos culturais são bens aos quais todos devem ter acesso; e das questões: como determinar quais os elementos que devem ser priorizados? O que manter e o que suprimir em detrimento do tempo? Qual a função estética desses elementos audiodescritos e como descrevê-los?; propomos refletir sobre os elementos visuais do espetáculo, suas funções e possibilidades de traduzilos verbalmente, ampliando dessa forma o entendimento da narrativa por pessoas com deficiência visual. Propomos assim, notas para descrição dos elementos visuais do espetáculo, os tornando verbais, valendo-se de teóricos das artes da cena e levando em consideração os elementos constituintes da cena, sua multiplicidade e complexidade.
\end{abstract}

PALAVRAS-CHAVE: Audiodescrição. Artes da Cena. Acessibilidade Cultural

\begin{abstract}
Audio-description (AD) is a resource that is gradually being studied, researched and operationalized in a perspective of cultural inclusion, providing the access and enjoyment of people with disabilities to various cultural products / spaces. Assuming that theater, dance, the visual arts, cinema, circus, performance, television programs, and other cultural goods / products are assets to which everyone must have access; and the questions: how to determine which elements should be prioritized? What to keep and what to suppress in detriment of time? What is the aesthetic function of these audiodescribed elements and how to describe them?; we propose to reflect on the visual elements of the show, their functions and possibilities of verbal translation, thus broadening the understanding of the narrative by visually impaired people. We propose, therefore, notes for the description of the visual elements of the spectacle, making them verbal, using theorists of the scene arts and taking into account the constituent elements of the scene, its multiplicity and complexity.
\end{abstract}

KEYWORDS: Audiodescription. Arts of the Scene. Cultural Accessibilit

\section{Resumen}

La audiodescripción (AD) es un recurso que viene paulatinamente siendo estudiado, investigado y operacionalizado desde una perspectiva de la inclusión cultural, proporcionando el acceso y la fruición

\footnotetext{
* Mestra em Artes cênica pelo Programa de Pós-graduação em Artes Cênicas da Universidade Federal do Rio Grande do Norte (PPGArc/UFRN). Especialista em Audiodescrição pela Universidade Feral de Juiz de Fora (UFJF). Professora substituta do Departamento de Artes cênicas da Universidade Feral da Paraíba (UFPB). Email: arahobi@gmail.com.
} 
de personas con discapacidad a diversos productos / espacios culturales. A partir del supuesto de que el teatro, la danza, las artes visuales, el cine, el circo, la performance, los programas televisivos, entre otros bienes / productos culturales son bienes a los que todos deben tener acceso; y de las cuestiones: ¿cómo determinar qué elementos deben priorizarse? ¿Qué mantener y qué suprimir en detrimento del tiempo? ¿Cuál es la función estética de estos elementos audiodescritos y cómo describirlos? proponemos reflexionar sobre los elementos visuales del espectáculo, sus funciones y posibilidades de traducirlos verbalmente, ampliando de esa forma el entendimiento de la narrativa por personas con discapacidad visual. Por lo tanto, proponemos así notas para la descripción de los elementos visuales del espectáculo, haciéndolos verbales, valiéndose de teóricos de las artes de la escena y teniendo en cuenta los elementos constituyentes de la escena, su multiplicidad y complejidad.

PALABRAS CLAVE: Audiodescripción. Artes de la Escena. Accesibilidad Cultural

\section{INTRODUÇÃO}

Diante das possibilidades abertas pela audiodescrição (AD), cada vez mais, pessoas estão tendo acesso a produtos e eventos culturais - a exemplo de espetáculos de teatro e dança, filmes, performances, circo, exposições artísticas, shows; como também a eventos - a exemplo de mostras, festivais, encontros, congressos - com o referido recurso; surgem também, trabalhos - a exemplo de artigos, tcc's, teses e dissertações - produzidos por pesquisadores e entusiastas da área em um meio que busca difundir, propor e operacionalizar metodologias de elaboração da AD nas diversas linguagens artísticas e bens/produtos culturais - a exemplo do teatro, da dança, da música, da literatura, de mostras e festivais.

É sabido que o processo inclusivo demanda a adaptação de recursos e estratégias para promover a tão falada inclusão, diante disso, é fundamental levar em conta que a audiodescrição se apresenta como um recurso para ampliar o entendimento, ao possibilitar que pessoas com deficiência visual acessem produtos culturais, de lazer e de informação. Tal recurso irá ampliar a compreensão além de favorecer o acesso mais detalhado por meio da audiodescrição, do universo imagético do produto apresentado, promovendo desta forma a quebra de barreiras comunicacionais, viabilizando o acesso ao conteúdo por todos.

Ao partirmos do pressuposto de que os elementos que compõem a cena, a saber: o ator, a voz, a música, o ritmo, o espaço, o tempo, a ação, o figurino, a maquiagem, o objeto, a iluminação, o olfato, o tato, o paladar e o texto; são regulados e organizados na perspectiva da construção de uma narrativa que pode se apresentar de forma multissequencial e multiforme ${ }^{1}$ ou não-sequencial, pretende-se uma discussão que leva em conta os elementos visuais do espetáculo e a sua tradução em palavras, na perspectiva da inclusão cultural/comunicacional de pessoas com deficiência visual em espetáculos teatrais. Segundo Murray (2003, p. 09):

\footnotetext{
${ }^{1}$ Termo utilizado por Murray (2003, p.10) em substituição ao termo não-linear como forma de compreensão dos novos formatos narrativos. Segundo a autora, “[...] histórias multissequenciais proporcionam ao interator a habilidade de navegar por um arranjo fixo de eventos de diferentes maneiras, todas elas bem definidas e significativas. O sentido mais profundo da obra emerge da compreensão desses caminhos entrecruzados, como na narrativa de um caso amoroso contado a partir de dois pontos de vista que se encontram. Uma história multiforme é aquela na qual múltiplas versões podem ser geradas a partir da mesma representação fundamental, como num jogo que pode ser repetido de modos diversos, [...]. Histórias multiformes podem ajudar-nos a perceber causas complexas de acontecimentos complexos, assim como a imaginar diferentes desfechos para uma mesma situação".
} 
[...] A narrativa é um de nossos mecanismos cognitivos primários para a compreensão do mundo. É também um dos modos fundamentais pelos quais construímos comunidades, desde a tribo agrupada em volta da fogueira até a comunidade global reunida diante do aparelho de televisão. Nós contamos uns aos outros histórias de heroísmo, traição, amor, ódio, perda, triunfo. Nós nos compreendemos mutuamente através dessas histórias, e muitas vezes vivemos ou morremos pela força que elas possuem.

A encenação, no sentido ao qual atribuímos o termo contemporaneamente, existe há mais de cem anos e mudou de forma radical a nossa concepção do teatro, apresentando-se como componente da história e evolução da peça, de seu sentido e apresentando-se como uma via de compreensão.

[...] a encenação, pelo menos aquela consciente de si mesma, surgiu quando parecia ser necessário mostrar no palco de que maneira o encenador poderia indicar a forma de ler uma obra dramática, que se tornou muito complexa para ser decifrada de maneira única, por um público homogêneo. A encenação dizia respeito, nessa circunstância, a uma obra literária, e não importa a qual espetáculo visual. Ela surgiu num momento de crise da linguagem e da representação, uma crise como tantas outras que o teatro conheceu (PAVIS, 2010, p. 45).

Se traçarmos tendências as quais o teatro se vinculou depois do surgimento da encenação, observamos que tal evolução, percebida não como uma supressão de formas antigas por novas, mas sim como um constante diálogo de influências recíprocas associadas às possibilidades trazidas pela evolução tecnológica e a expansão de suportes, recursos e dispositivos, constatamos que foram gestadas propostas estéticas que enfatizam elementos diversos, a exemplo da iluminação, do espaço cênico, da emancipação da prática cênica em relação ao texto e seu autor, a formação sistemática do ator, a autonomia da cena, o teatro enquanto arma histórica e política, o teatro antropológico, o minimalismo, etc. Proposições que coexistem na contemporaneidade, dialogam e se aplicam de acordo com as propostas estéticas e/ou políticas almejadas, e muitas vezes integram de forma híbrida um mesmo espetáculo.

A Encenação, outrora fechada em seus mecanismos de regulagem voltados para transposição e ilustração do texto, flerta atualmente com traços estilísticos atribuídos inicialmente à performance, buscando dessa forma não uma substituição do termo, mas uma complementação. Na contemporaneidade, devido ao hibridismo e confluência das diversas artes, a noção de encenação se expande enriquecendo-a e diversificando-a, o que nos obriga, como propõe Pavis (2010, p. 390) "a repensar o mecanismo de regulagem que preside a criação estética desse objeto chamado encenação".

Posto isso, propomos refletir sobre os elementos visuais do espetáculo, suas funções e possibilidades de traduzi-los verbalmente, tendo como pano de fundo as discussões de pesquisadores das artes da cena, ampliando dessa forma o entendimento da narrativa por pessoas com deficiência visual.

Abordaremos, a seguir, elementos visuais das artes do espetáculo, tal listagem não pretende ser restritiva - uma vez que o espetáculo assimila recursos, suportes e dispositivos referentes ao seu contexto de época - mas descrever os recursos mais usuais que aparecem com mais frequência. Apesar da abordagem individual de cada componente, vale ressaltar que 
os mesmos atuam em conjunto na construção da narrativa, tal desmembramento visa abordálos de forma mais didática.

\section{Ator / Performer}

Elemento fundamental para a efetivação do fenômeno teatral, "o ator, desempenhando um papel ou encarnando uma personagem, situa-se no próprio cerne do acontecimento teatral. Ele é o vínculo vivo entre o texto do autor, as diretivas de atuação do encenador e o olhar e a audição do espectador" (PAVIS, 2007, p. 30). Mas, como descrever o trabalho do ator? De quais teorias se valer? Como transformar em palavras o que é imagético em sua atuação? O trabalho do ator, assim como os demais elementos relativos ao fazer teatral estão constantemente em evolução e, filiado a proposições estéticas e culturais, o que inviabiliza pensar, ou propor, uma teoria global para o ator. Ao nos referirmos aos atores orientais, por exemplo, nossa tarefa se mostraria menos árdua, uma vez que culturalmente a arte de ator é mais técnica, ou seja, vinculada a formas codificadas e reproduzíveis. Já o ator ocidental, está envolto em uma tradição ligada à improvisação, a livre expressão e, por vezes, a psicologização da personagem.

\footnotetext{
No teatro, as emoções são sempre manifestadas graças a uma retórica do corpo e dos gestos nos quais a expressão emocional é sistematizada, ou mesmo codificada. Quanto mais as emoções são traduzidas em atitudes ou em ações físicas, mais elas se libertam das sutilezas psicológicas do indizível e da sugestão (PAVIS, 2005, p.50).
}

No entanto, o ator não necessariamente imita uma pessoa real, ele pode, através de convenções e/ou por relato verbal e gestual, propor ações. Pavis (2005), ao sugerir algumas observações sobre a metodologia da análise do ator contemporâneo ocidental, elucida a situação de ator e os traços específicos de sua atuação:

$\mathrm{O}$ ator se constitui como tal assim que um espectador, ou seja, um observador externo, o olha e o considera como "extraído" da realidade ambiente e portador de uma situação, de um papel, de uma atividade fictícia ou pelo menos distinta de sua própria realidade de referência. Mas não basta que tal observador decida que tal pessoa representa uma cena e, logo, que é um ator [...], é preciso também que o observado tenha consciência de representar um papel para seu observador e que assim a situação teatral esteja claramente definida. Quando a convenção está estabelecida, tudo o que o observador faz ou diz não é mais vendido pelo preço que se comprou, mas como ação ficcional que tem sentido e verdade apenas no mundo possível no qual observador e observado convencionam se situar. Assim procedendo, ao definir a atuação como uma convenção ficcional estamos no caso do ator ocidental que finge ser um outro; pelo contrário, o performer oriental (o atorcantor-dançarino), quer cante, dance ou recite, realiza essas ações reais como ele mesmo, como performer, e não como personagem fingindo ser um outro ao se fazer passar como tal aos olhos do espectador, se o termo performer é cada vez mais usado, no lugar de "ator", é para insistir na ação completada pelo ator, por oposição à representação mimética de um papel. O performer é antes de tudo aquele que está presente de modo físico e psíquico diante do espectador (PAVIS, 2005, p. 51-52). 
$\mathrm{Na}$ contemporaneidade, o ator nem sempre representa mimeticamente "uma pessoa verdadeira, um indivíduo formando um todo, a uma série de emoções” (PAVIS, 2005, p. 55), a personagem, outrora "cópia-substância de um ser" (UBERSFELD, 2005, p. 69) tornou-se polimorfa e, apresenta-se constantemente estilhaçada, dividida, lacerada, distribuída em vários intérpretes, além de construir significações valendo-se de partes isoladas de seu corpo que, estarão em constante diálogo com os demais elementos da encenação, sugerindo dessa forma a realidade narrada.

Mas, como descrever o ator e aquele que será o seu duplo, ao qual irá emprestar "seu corpo, seus traços, sua voz, sua energia" (RYNGAERT, 1995, p. 126), levando em consideração as diferentes estéticas teatrais, suas concepções e usos Michel Bernard (apud PAVIS, 2005, p.58-59) descreve sete referencias relativa à corporalidade do ator, de grande valia para notarmos e descrevermos os diferentes usos do corpo em cena: 1 - A extensão e a diversificação do campo da visibilidade corporal (nudez, mascaramento, deformação etc.), em suma, de sua iconicidade. 2 - A orientação ou a disposição das faces corporais relativamente ao espaço cênico e ao publico (frente, costas, perfil, três - quartos etc.). 3 - As posturas, ou seja, o modo de inserção no solo e mais amplamente o modo de gestão da gravitação corporal (verticalidade, obliquidade, horizontalidade...). 4 - As atitudes, ou seja, as configurações das posições somáticas e segmentárias em relação com o ambiente (mão, antebraço, braço, tronco/cabeça, perna...). 5 - Os deslocamentos ou as modalidades da dinâmica de ocupação do espaço cênico. 6 - As mímicas como expressividade visível do corpo (mímicas fisionômicas e gestuais) em seus atos úteis como supérfluos, e, por conseguinte, do conjunto dos movimentos anotados. 7 - A vocalidade, ou seja, a expressividade audível do corpo e/ou dos substitutos e complementos (barulhos orgânicos naturais ou artificiais: como os dedos, os pés, a boca etc.).

\section{Figurino}

A história do figurino de teatro, como aponta Pavis (2007) está ligada à da moda da vestimenta, porém este se apropria e a ressignifica. $O$ teatro sempre se valeu do figurino, $o$ associando ao contexto de época e estéticas praticadas. Em sua evolução, o figurino vivenciou fases em que o associava ao ritual; ao virtuosismo em que os atores se vestiam com heranças ganhas das cortes que os protegiam, sem estabelecer um elo com a personagem representada; ao verossímil, "[...] e o figurino, enquanto elemento visual, estabelece um essencial elo de significação entre o personagem e o contexto espacial em que este evolui" (ROUBINE, 1998, p. 123).

Utilizados com frequência de forma evocativa ou representativa com base em convenções facilmente identificáveis, o figurino teatral "[...] portador de signos, como projeção de sistemas sobre um objeto-signo relativamente à ação, ao caráter, à situação à atmosfera (PAVIS; 2007, p. 169), é ao mesmo tempo significante e significado em constante diálogo com o corpo do ator.

[...] o figurino, sempre presente no ato teatral como signo da personagem e do disfarce, contentou-se por muito tempo com o simples papel de caracterizador encarregado de vestir o ator de acordo com a verossimilhança de uma condição ou de uma situação. Hoje, na representação, o figurino conquista um lugar muito mais ambicioso; multiplica suas funções e se integra ao trabalho de conjunto em cima dos 
significantes cênicos. Desde que aparece em cena, a vestimenta converte-se em figurino de teatro: põe-se a serviço de efeitos de amplificação, de simplificação, de abstração e de legibilidade (PAVIS, 2007, p. 168).

O figurino teatral teve que esperar as evoluções advindas do século XX para se integrar em uma perspectiva estética mais autônoma. Na contemporaneidade os figurinos assumem funções diversificadas, associados a proposições estéticas e técnicas. Pavis (2007, p. 170) aponta o paradoxo do figurino no trabalho teatral contemporâneo:

[...] ele multiplica suas funções, vai além do mimetismo e da sinalização, coloca em questão as categorias tradicionais demasiado estratificadas (cenário, acessório, maquiagem, máscara, gestualidade etc.); o "bom" figurino é aquele que retrabalha toda a representação a partir de sua flexibilidade significante.

Segundo Pavis (2005, p. 164), as grandes funções do figurino são: A caracterização: meio social, época, estilo, preferências individuais; a localização dramatúrgica para as circunstancias da ação; identificação ou o disfarce da personagem; a localização do gestus ${ }^{2}$ global do espetáculo, ou seja, da relação da representação, e dos figurinos em particular, como universo social: "Tudo o que, no figurino, confunde a clareza dessa relação contradiz, obscurece ou falsifica o gestus social do espetáculo, é ruim; tudo o que, pelo contrário, nas formas, cores, substâncias e seu embricamento, ajuda a leitura desse gestus, tudo isso é bom.",

O figurino em relação com o corpo do ator atuará na construção da personagem. Escolhas como material, textura, peso, corte, etc., irá reverberar no ajustamento da personagem por meio da gestualidade e da roupa. Quanto à nudez, Pavis (2005, p. 165) elucida que: "não é o grau zero do figurino - seria antes o figurino que, por sua familiaridade e sua adequação aos nossos valores, representa o grau zero. A nudez pode acolher todas as funções: erótica, estética, 'estranheza inquietante' etc.".

Os elementos visuais estão em constante diálogo entre si, como também com outros fatores referentes ao fazer teatral. Para uma melhor compreensão da discussão ora abordada, se faz necessário compreender, mesmo que grosso modo, a distinção entre espaço cênico e espaço dramático, de fundamental importância, uma vez que, o figurino é muitas vezes uma cenografia $^{4}$ ambulante, e estabelece uma relação dialógica com o espaço.

\footnotetext{
2 [...] o gestus se compõe de um simples movimento de uma pessoa diante de outra, de uma forma social ou corporativamente particular de se comportar. Toda ação cênica pressupõe uma certa atitude dos protagonistas entre si e dentro do universo social: é o gestus social. O gestus fundamental da peça é o tipo de relação fundamental que rege os comportamentos sociais (servilismo, igualdade, violência, astúcia etc.). O gestus se situa entre a ação e o caráter (oposição aristotélica de todo teatro): enquanto ação, ele mostra a personagem engajada numa praxis social; enquanto caráter, representa o conjunto de traços próprios a um indivíduo. O gestus é sensível, ao mesmo tempo, no comportamento corporal do ator e em seu discurso: um texto, uma música podem, na verdade, ser gestuais se apresentam um ritmo apropriado ao sentido do que ele está falando. (PAVIS, 2007, p. 187)

${ }^{3}$ Apud Barthes.

${ }^{4}$ [...] a cenografia é uma escritura no espaço em três dimensões. [...]. Corresponde tanto a uma evolução autônoma da estética cênica quanto a uma transformação em profundidade da compreensão do texto e de sua representação cênica.

Hoje, a cenografia concebe sua tarefa não mais como ilustração ideal e unívoca do texto dramático, mas como dispositivo próprio para esclarecer (e não mais para ilustrar) o texto e a ação humana, para figurar uma situação
}

Educação e Fronteiras On-Line, Dourados/MS, v.10, n.28 p.77-89, jan./abr. 2020 
O espaço cênico refere-se ao "espaço real do palco onde evoluem os atores, quer eles se restrinjam ao espaço propriamente dito da área cênica, quer evoluam no meio do público." (PAVIS, 2007, p. 132). Já o espaço dramático está associado ao "qual o texto fala, espaço abstrato e que o leitor ou o espectador deve construir pela imaginação (ficcionalizando)" (PAVIS, 2007, p.132).

Pavis (2005, p. 166-167) aponta ainda, funções significantes do figurino no continuum espaço-tempo-ação-luz: o figurino preenche e constitui um espaço, nem que seja apenas pela maneira pela qual valoriza o corpo em seus deslocamentos; ele se estende mais ou menos, podendo materializar um época, mas também um ritmo e uma maneira de voar ao vento; ele participa da ação, sempre colado na pele do ator, ou transportado em um volume cinético, sempre vestido pelo ator, a não ser que se transforme em uma crisálida abandonada por ele; ele capta mais ou menos luz, estruturando e ritmando as mudanças de intensidade luminosa.

\section{Luz}

Por séculos, o teatro se valeu da luz do sol, Camargo (2012, p. 02) explicita que "durante esse período de teatro produzido sob fonte natural, a luz não era outra coisa senão ela mesma, como pura manifestação". E os recursos de luz artificial, a exemplo de velas, tochas e archotes eram utilizados na perspectiva de se dar a ver, ou seja, como iluminantes quando as apresentações prolongavam-se até a noite.

Com a evolução dos recursos, o teatro foi ampliando paulatinamente o uso da luz natural e criando mecanismos para manipulá-la, a exemplo de artifícios para captar e redirecionar a luz por meio de "escudos de madeira revestidos por lâminas de mica reflexiva, distribuídos por diversos pontos da plateia" (CAMARGO, 2012, p. 04); como também, o uso de vitrais como filtro de luz.

No entanto, é a partir da transferência do teatro para salas fechadas no século XVI que surgem os problemas relativos à visibilidade. Ao teatro, coube recorrer a recursos que iluminassem o espaço cênico, o tornando visível; todavia, esse problema se apresentava em apresentações noturnas, fazendo com que várias velas fossem instaladas nos teatros. Nessa época, vários tipos de velas foram utilizados, como também, o emprego de novos recursos que iam surgindo, a exemplo dos pavios enrolados, que conferiam melhor intensidade e brilho da luz, além de serem mais seguros e produzirem menos fumaça. Paralelamente as pesquisas relacionadas a fontes combustíveis experimentaram-se novos meios de instalação das fontes de luz. Nesse período, várias foram as mudanças decorrentes nas fontes de luz artificial, culminando com o surgimento da luz a gás. "A iluminação a gás vem resolver de forma mais satisfatória a questão da visibilidade nos teatros. Longe de ser ainda a solução ideal, o gás representou um grande progresso em relação à precariedade de tochas, velas, lâmpadas de azeite e querosene" (CAMARGO, 2012, p.14).

No século XIX, surge à iluminação elétrica, e junto com ela, "uma mudança historicamente importante: o obscurecimento da plateia" (CAMARGO, 2012, p. 17). Inicialmente utilizada para acentuar o ilusionismo das montagens naturalistas, possibilitando mais tarde experimentações que revolucionariam o uso mimético da luz, como fez a dançarina

de enunciação (e não mais um lugar fixo), e para situar o sentido da encenação no intercâmbio entre um espaço e um texto. (PAVIS, 2007, p. 45) 
americana Loie Fuller, que introduziu o uso de cores nas artes cênicas, redimensionando com seu uso o espaço cênico e dando papel de protagonista à iluminação.

A partir de 1890, as proposições cenográficas simbolistas investiram na ruptura com o modelo de representação naturalista. Encontrando no recurso técnico da iluminação possibilidades para novas experimentações, eles desligaram-se da preocupação com a ilusão e imitação naturalistas, buscando representações simbólicas do inconsciente humano. Sob forte influência de artistas como o suíço Adolphe Appia e o inglês Gordon Craig, o simbolismo teatral na virada do século XIX para o século XX buscou conceitos inovadores e modificações estéticas a partir da iluminação.

Com a plateia totalmente no escuro, a iluminação cênica adquire outro sentido e, evidentemente, mais importância sobre o espetáculo. A partir de então, surge uma separação nítida entre palco e plateia, permitindo o surgimento de uma nova percepção tanto da luz quanto da cena (CAMARGO, 2012, p. 18).

A luz elétrica soluciona definitivamente o problema da visibilidade em salas fechadas e, junto a sua intensidade houve o aprimoramento técnico e o surgimento de novos recursos que, dentre outras coisas, permitem selecionar, enfatizar, aproximar ou distanciar o objeto dos olhos. Dessa forma, como aponta Camargo (2012, p. 21), “[...] a discussão tomou outro rumo: o que fazer com todos os recursos inventados ou, mais precisamente, qual seria o papel da luz em relação à cena?”. Para Pavis (2007, p. 202):

\begin{abstract}
A luz intervém no espetáculo; ela não é simplesmente decorativa, mas participa da produção de sentido do espetáculo. Suas funções Dramatúrgicas ou semiológicas são infinitas: iluminar ou comentar uma ação, isolar um ator ou um elemento da cena, criar uma atmosfera, dar ritmo à representação, fazer com que a encenação seja lida, principalmente a evolução dos argumentos e dos sentimentos etc. situada na articulação do espaço e do tempo, a luz é um dos principais enunciadores da encenação, pois comenta toda a representação e até mesmo a constitui, marcando o seu percurso. Material milagroso de inigualáveis fluidez e flexibilidade, a luz dá o tom de uma cena, modaliza a ação cênica, controla o ritmo do espetáculo, assegura a transição de diferentes momentos, coordena os outros ritmos cênicos colocando-os em relação ou isolando-os.
\end{abstract}

Pavis (2005, p.180) ressalta a importância das cores utilizadas na iluminação:

\begin{abstract}
É a iluminação que cria a cor, deve haver então uma combinação mínima entre cenógrafo, o figurinista e o iluminador para que as escolhas cromáticas não se aniquilem. O espectador estará atento aos tons utilizados: quentes para uma sensação agradável; frios para suscitar a tristeza; médios para uma impressão neutra e calma. As colorações escolhidas suscitam emoções e sensações por obra da luz (clareza) e da cor (tom).
\end{abstract}

O autor pontua ainda, as relações entre a luz e outros componentes da cena, a saber: a cenografia - ela faz ou não penetrar a luz natural. A luz artificial escolhe entre iludir ou fazer desaparecer tal elemento do cenário. Mudando de direção, pode sugerir a progressão do dia [...]. pode igualmente desorientar o observador. (PAVIS, 2005, p.181); o figurino - as roupas recebem a luz de modo particularmente fácil: suas dobras são valorizadas, seus tons são 
tornados visíveis e variáveis segundo o tipo de luz e de filtro de gelatina utilizado (PAVIS, 2005, p.181); a maquiagem - é valorizada positivamente ou negativamente. A cor abóbora ou laranja realçará agradavelmente o tom da pele; a cor verde ou azul, pelo contrário, resultará numa pele cinza, de aspecto particularmente sinistro. A maquiagem é quase sempre uma necessidade (PAVIS, 2005, p.181); o ator - o ator como um todo é às vezes afetado pela luz: sua energia é valorizada ou, pelo contrário, atenuada. Sua relação com o espectador é transparente, sobretudo com a luz geral, ou perturbada se ele é cegado por uma torrente de luz ou reduzido a uma voz na penumbra (PAVIS, 2005, p.181).

Segundo Pavis (2007, p.201-202), "O termo iluminação vem sendo substituído, cada vez mais, na prática atual, pelo termo luz, provavelmente para indicar que o trabalho da iluminação não é iluminar um espaço escuro, mas, sim, criar a partir da luz".

\title{
Maquiagem
}

Utilizada no teatro ocidental inicialmente de forma ritualística, passa a ser usada a partir do século XVI como maquiagem de beleza, atingindo o exagero no século XVIII; no entanto, é a partir da introdução inicialmente da iluminação a gás e, depois, da luz elétrica que ela evolui como elucida Pavis (2007), sendo a partir de então que, o teatro recorre à maquiagem para adaptar a cor da pele a iluminação cênica.

\footnotetext{
O cenário colado ao corpo do ator se torna figurino, o figurino que se inscreve em sua pele se torna maquiagem [...].

A maquiagem não é, no entanto, uma extensão do corpo como podem ser a máscara, o figurino ou o acessório. [...]. É, melhor dizendo, um filtro, uma película, uma fina membrana colada no rosto: nada está mais perto do corpo do ator, nada melhor para servi-lo ou traí-lo que esse filme tênue (PAVIS, 2005, p. 170).
}

Convencionou-se no teatro que, os traços expressivos da maquiagem devem ser aumentados de maneira a parecerem naturais devido à distância entre o atuante e a plateia. A perspectiva e a escala desse aumento podem assim ficarem deformadas e o observador deve então permanecer consciente dessa convenção cênica (PAVIS, 2005, p. 171).

\begin{abstract}
Segundo a estética da encenação, a maquiagem terá uma tendência para servir o verossímil das situações (uso realista ou naturalista) para produzir mimeticamente os rostos das personagens, ou pelo contrário, para sublinhar seus próprios procedimentos, a se tornar um fim em si, uma pintura facial ou corporal, que não deve ser mais colocada a serviço dos outros signos, mas em concentrar os olhares sobre sua própria prática autônoma. (PAVIS, 2005, p. 171-172).
\end{abstract}

Pavis (2007, p. 231-232) enumera algumas funções da maquiagem, de grande utilidade para elaboração de roteiros de AD: embelezar - o papel de composição obriga o maquiador a prodígios de reparos e de melhoramentos: retirar bolsas dos olhos, disfarçar queixo duplo, eliminar uma espinha; codificar o rosto - certas tradições teatrais, como o teatro chinês, baseiam-se num sistema puramente simbólico de correspondência entre cores e características sociais: branco para intelectuais, vermelho para os heróis leais, azul escuro para as 
personagens orgulhosas, prata para os deuses etc; teatralizar a fisionomia - figurino vivo do ator, a maquiagem faz o rosto passar do animado ao inanimado, flerta com a máscara, quando se torna uma máscara mais ou menos opaca e flexível que às vezes utiliza a mobilidade do rosto. [...]. $\mathrm{Na}$ arte do semblante, a maquiagem pode, ao mesmo tempo, acentuar a teatralidade, a maquinaria facial [...] e dar novamente impressão de vida, renaturalizar e interiorizar" a expressão mímica. Ela joga com a ambiguidade constitutiva de representação teatral: mescla de natural e artificial, de coisa e de signo; estender a maquiagem - ela não mais se limita ao rosto, o corpo inteiro pode ser pintado. [...]. A maquiagem passa a ser um cenário ambulante, estranhamente simbólico; ela não mais caracteriza de maneira psicológica e, sim, contribui para a elaboração de formas teatrais do mesmo modo que os outros objetos da representação (máscara, iluminação, figurino etc.). Ao renunciar a seus efeitos psicológicos, assume sua qualidade de sistema significante, que faz dela um elemento estético total da encenação.

\section{Objeto}

Como elucida Ubersfeld (2005, p. 117), “o espaço teatral não é vazio: ele é ocupado por uma série de elementos concretos cuja importância relativa é variável. São eles: os corpos dos atores; os elementos do cenário; os acessórios.”.

\footnotetext{
O termo objeto tende a substituir, nos escritos críticos o termo acessório ou cenário. A neutralidade, até mesmo a vacuidade da expressão, explica seu sucesso para descrever a cena contemporânea, que participa tanto do cenário figurativo, da escultura moderna ou da instalação quanto da plástica animada dos atores (PAVIS, 2007, p. 265).
}

O termo refere-se, dessa forma a esses elementos concretos que, se apresentam por vezes de forma flexível, manipulável, mutável, podendo assumir o papel de cenário, de adereço, de personagem.

[...] Uma personagem pode ser um locutor, mas pode também ser um objeto da representação, do mesmo modo que um móvel: a presença muda ou a imobilidade de um corpo humano pode ser significante como a presença de um objeto; um grupo de atores pode figurar um cenário; é possível que seja mínima a diferença entre a presença de um guarda armado e a de armas representando a força ou a violência. Por isso, fica difícil fazer coincidir as três categorias de objetos com três tipos de funcionamento autônomos: um acessório, um ator, um elemento do cenário pode ter funções intercambiáveis (UBERSFELD, 2005, p.118).

Pavis (2007, p. 265-266) elenca algumas funções do objeto: mimese do âmbito da ação - o objeto, a partir do momento que é identificado pelo espectador, situa imediatamente o cenário. Quando é importante para a peça caracterizar o ambiente cênico, o objeto deve apresentar alguns traços distintivos; intervenção no jogo - o objeto teatral é usado para certas operações ou manipulações. Esta função pragmática é particularmente importante quando a cena mostra homens ou mulheres em ocupações cotidianas. Quando o cenário não é figurativo, certos elementos servem de máquina de representar [...]. O objeto é então menos 
funcional do que lúdico: ele "produz" sentidos cenográficos que se enxertam no texto.; abstração e não-figuração - quando a encenação se organiza unicamente a partir do jogo do ator, sem pressupor um local de ação específico, o objeto é muitas vezes abstrato, não é utilizado dentro de um uso social e assume um valor de objeto estético (ou poético); paisagem mental ou estado d'alma - o cenário da uma imagem subjetiva do universo mental ou afetivo da peça: nele, raramente o objeto é figurativo, mas fantástico, onírico ou "lunar". O fim buscado é criar familiaridade visual com o imaginário das personagens da peça.

Pavis (2007, p. 266) nos apresenta ainda, diferentes formas assumidas pelo objeto, que nomeia de polimorfia do objeto: desvio de sentido - o objeto não-mimético presta-se a todos os usos, em particular àqueles que podiam parecer os mais distantes dele [...]. Por uma sequência de convenções, o objeto se transforma num signo das coisas mais variadas; níveis de apreensão - $\mathrm{O}$ objeto não é reduzido a um único sentido ou nível de apreensão. $\mathrm{O}$ mesmo objeto é muitas vezes utilitário, simbólico, lúdico, conforme os momentos da representação e, sobretudo, conforme a perspectiva da apreensão estética; desmultiplicação dos signos - não existe objeto bruto que já não tenha sentido social e que não se integre a um sistema de valores. O objeto é consumido tanto por sua conotação quanto por sua funcionalidade primeira. Além disso, o objeto teatral é sempre signo de algo. De modo que ele se acha preso num circuito de sentidos (de equivalências) e remetido por conotações a uma grande quantidade de significações que o espectador o faz "experimentar" sucessivamente; artificialização/materialização - por causa desse circuito de sentidos, o objeto funciona como significado, o que quer dizer que sua materialidade (seu significante) e sua identidade (seu referente) tornam-se inúteis e integram-se ao processo global da simbolização. Todo objeto posto em cena sofre esse efeito de artificialização/abstração, o que não ocorre sem cortá-lo do mundo real e intelectualizá-lo. Este é, sobretudo, o caso dos objetos simbólicos não-utilitários que designam seu referente de modo abstrato, até mesmo mítico (símbolos religiosos e idealizações da realidade).

Mas a tendência inversa - a do objeto material, intraduzível em categorias abstratas está igualmente presente na encenação atual. O cenário escolhe um ou dois materiais básicos (madeira, couro, metal, tapeçaria, têxteis) conforme a atmosfera material da peça e o tom básico da representação. Estes materiais são apenas trabalhados; não remetem a significado algum, agem como matéria-prima da qual é preciso extrair um sentido e sentir a sensação conforme a situação cênica. Muitas vezes os objetos se veem elevados ao estatuto de plástica móvel, atuando para e com a cena, produzindo, graças a sua dimensão poética, teatral e lúdica, uma miríade de associações mentais no espectador.

Frequentemente na fronteira de outros elementos da representação, os objetos podem assumir diferentes identidades, a exemplo da carcaça de geladeira no espetáculo Quincas que, ora é elevador, ambulância, embarcação, ônibus, mesa, transformando-se assim em máquina de jogo estimulando a imaginação do espectador.

Diante do exposto, fica evidente a não existência de uma categorização hermética para a diversidade de objetos ao qual a cana recorre. Podendo, como nos propõe Pavis (2005, p.177) descrever as formas, numerar os materiais, distinguir função utilitária e uso estético.

\section{CONSIDERAÇÕES FINAIS}


Ao se criar um roteiro de $\mathrm{AD}$ para espetáculos teatrais, é preciso levar em consideração elementos imagéticos que complementam a narrativa, a exemplo de figurinos, caracterização, iluminação, cenário, objetos de cena, dentre outros. Mas, como determinar quais os elementos que devem ser priorizados? O que manter e o que suprimir em detrimento do tempo? Qual a função estética desses elementos audiodescritos e como descrevê-los? Perguntas como estas devem ser levadas em consideração, para que ocorra de fato não apenas o entendimento do que acontece na cena, mas que se absorva sua essência.

Acreditamos que, por se tratar de algo relativamente novo, a AD ainda se encontra em processo de construção de propostas metodológicas nas suas diversas aplicações. A associação de profissionais capacitados, com conhecimento da linguagem / produto a ser audiodescrito, além de uma equipe formada por videntes e pessoas com deficiência visual, é de extrema importância.

E primordial buscar uma maior compreensão das relações que se estabelecem entre a $\mathrm{AD}$, as artes da cena na atualidade e as metodologias aplicadas na elaboração de roteiros, ampliando as propostas metodológicas.

\section{REFERÊNCIAS}

CAMARGO, Roberto Gill. Função estética da luz. 2. ed. São Paulo: Perspectiva, 2012.

HOBI, Larissa. Interface Cena e Tecnologia: composições cênicas mediadas. 2013. 130f. Dissertação (Mestrado em Artes Cênicas) - Universidade Federal do Rio Grande do Norte, Natal, 2013.

HOBI, Larissa. Elementos Visuais do Espetáculo: apontamentos para elaboração de audiodescrição. 2015. 85f. Trabalho de conclusão de curso (Especialização) - Universidade Federal de Juiz de Fora, Juiz de Fora, 2015.

HURTADO, C. J. (ed.). Traducción y accesibilidad. Subtitulación para sordos y audiodescripción para ciegos: nuevas modalidades de Traducción Audiovisual. Frankfurt AM Main: Peter Lang, 2007.

MOTTA, Lívia Maria Villela de Mello; ROMEU FILHO, Paulo (org.) Audiodescrição: transformando imagens em palavras. São Paulo: Secretaria de Estado da Pessoa com Deficiência, 2010.

MURRAY, Janet H. Hamlet no holodeck: o futuro da narrativa no ciberespaço. São Paulo: Itaú Cultural: Unesp, 2003. 
PAVIS, Patrice. A Encenação contemporânea: origens, tendências, perspectivas. São Paulo: Perspectiva, 2010.

PAVIS, Patrice. A análise dos espetáculos. São Paulo: Perspectiva, 2005.

ROUBINE, Jean-Jacques. A linguagem da encenação teatral, 1880 - 1980. 2. ed. Rio de Janeiro: Jorge Zahar, 1998.

RYNGAERT, Jean-Pierre. Introdução à análise do teatro. São Paulo: Martins Fontes, 1995.

RYNGAERT, Jean-Pierre. Ler o teatro contemporâneo. 2. ed. São Paulo: Martins Fontes. 2013

SARRAZAC, Jean-Pierre (Org.). Léxico do drama moderno e contemporâneo. São Paulo: Cosac Naify, 2012.

SASSAKI, Romeu Kazumi. Inclusão: acessibilidade no lazer, trabalho e educação. Revista Nacional de Reabilitação (Reação), São Paulo, Ano XII, mar./abr. 2009, p. 10-16.

SASSAKI, Romeu Kazumi. Sete Dimensões da Acessibilidade. Palestra Pessoas com deficiência no mercado de trabalho e acessibilidade, Curitiba, 2012.

UBERSFELD, Anne. Para ler o teatro. São Paulo: Perspectiva, 2005. Disponível em: http://www.vercompalavras.com.br / http://www.blogdaaudiodescricao.com.br/. Acesso em: $<08$ de jan.de 2016>.

Recebido em: 24/10/2019

Aprovado em: 19/12/2019 